\title{
Destoning of fine coal in a fluidized bed
}

\author{
Marco le Roux ${ }^{*}, \mathrm{PhD}$ (Corresponding author) \\ Associate professor, telephone: +27 18299 1990, E-mail: marco.leroux@nwu.ac.za \\ Quentin Campbell ${ }^{*}, \mathrm{PhD}$ \\ Associate professor, telephone: +27 18299 1993, E-mail: quentin.campbell@nwu.ac.za \\ Danie Langner ${ }^{*}$ \\ Post graduate student, telephone: +27 76984 4081, E-mail: langner.danie@gmail.com \\ *School of Chemical and Minerals Engineering, North-West University, Private Bag X6001, \\ Potchefstroom 2520, South Africa,
}

\begin{abstract}
Water scarcity is driving the development of dry coal beneficiation processes. A lot of research has gone into the development of dry dense medium fluidized bed technology (DMFB), especially in China. However, these processes focus mainly on $+6 \mathrm{~mm}$ particles while little work has gone into the development of dry processes for $-2 \mathrm{~mm}$ particles. This paper focusses on the possibility to remove mineral matter (high density particles) from valuable coal fines $(-2+1 \mathrm{~mm}$ and $-1+0.5 \mathrm{~mm})$ by using a fluidized bed operated with and without added vibration, while adding dense media (magnetite, sand and fine coal discards). As a control the bed was also operated without any dense media.

A fluidized bed column was designed and constructed by clamping several individual rings on top of one another. This design helped with the sampling of the coal in the bed. After a test run, each individual ring could be removed and the coal inside analysed for ash percentage and calorific value. The results clearly indicated that this process is viable by removing high ash value material in the bottom layer of the bed, leaving the rest of the bed to be significantly lower in ash value and as a result higher in the calorific value of the coal. It confirmed previous work by the authors that showed a negative overall performance of the bed when media was added, due to difficulty in separating the media from the fine coal particles. By vibration the bed, the sharpness of separation did increase slightly.
\end{abstract}

Key words: dry coal beneficiation, fine coal, fluidized bed

\section{Introduction}

Although water is one of the most abundant resources on the earth, there are several arid regions that sees very little to no rainfall per annum. This is particularly true for some countries with vast coal reserves such as India, China, Russia, Mongolia and South Africa, some of which have a shortage of clean process water near coal reserves. Transporting water to these areas with a shortage thereof would be very expensive and unpractical to maintain (Houwelingen \& de Jong, 2004:335).

Throughout most of South Africa water is scarce during winters (Philander, 2010). A detailed study into South Africa's water resources revealed that only $1200 \mathrm{~m}^{3}$ of fresh water is available per capita per year. Moreover, South Africa has an average of $464 \mathrm{~mm}$ of rainfall per year (Zhao et al., 2010a). To put this into perspective, a study indicates that for one ton of coal, $3-5$ tons of process water is needed in a wet jigging process (Chen \& Wei, 2003). In the Waterberg area, which has one of the largest coal deposits in South Africa, large scale plant development could be limited due to insufficient water supplies (Eberhard, 2011). The same applies to coal resources in Botswana. 
New discoveries of vast coal reserves were made in Mongolia recently. More than 200 coal deposits were found which consists of 152 billion tons of coal (Erdenetsogt et al., 2009). China, which is geographically situated next to Mongolia, is the largest steel producer in the world. According to Levin (2012) there is sufficient coal in Mongolia to fuel China's substantial demand for the next 50 years. However, Mongolia is a perfect example of a country with enormous coal reserves but not enough water to run economically viable wet beneficiation processes in some regions. The only viable alternative is to implement dry beneficiation.

Coal is primarily washed using dry or wet processes. Wet beneficiation methods require vast amounts of process water as emphasized by Chen \& Wei (2003), but yield much sharper separation efficiencies than dry processes. Considering the major problem of a clean water shortage worldwide, the focus of research should be on effective dry beneficiation methods of coal (Yang et al., 2012a).

A dry beneficiation method which could be a possible solution to the problem is the dense medium fluidized bed (DMFB) technology. This technology is classified as a dense medium beneficiation, which uses gas and solid particle interactions as well as the law of gravity to stratify coal according to density (Luo et al., 2007).

Over the years several research articles have been written on every aspect of fluidization, and it was found that this technology holds many advantages especially in the coal washing industry (Mohanta et al., 2013). Chen \& Yang (2003) describes these advantages to be:

High precision: Coal with a size range of $50 \mathrm{~mm} \times 6 \mathrm{~mm}$ can effectively be separated with Ep values of 0.05-0.07. These values compare favourably with the existing heavy medium wet beneficiation.

Low investment: The same capacity dry beneficiation plant can be constructed for half the cost compared to a wet beneficiation plant. This is due to the fact that no complicated and costly slurry treatment is needed when handling dry coal.

No environmental pollution: This technology only requires low pressure compressed air. It also operates smoothly with very little noise pollution. The dust emitted by the equipment is within environmental laws.

Wide ranges of beneficiating densities: Beneficiating densities ranging from 1.3 to $2.2 \mathrm{~g} / \mathrm{cm} 3 \mathrm{can}$ be created by adding magnetite powder to the bed. Thus this technology can either remove heavy gangues or lower density clean coal depending on the required product.

No moisture penalties: Because only air is used in this process, cleaning water is not needed and the product coal is not penalized due to exceeding moisture levels (Luo et al., 2008).

Product thermal quality: A dryer product with a higher calorific value per ton of coal is produced (Sahu et al., 2009).

Transportation costs: Due to low moisture content, transportation of the coal does not include the additional cost of transporting the weight of water (England et al., 2002).

However, research on dry coal beneficiation methods is mostly conducted on coarse coal $(+6 \mathrm{~mm})$ which yielded promising results but are not applicable to fine coal fractions $(-2000+500 \mu \mathrm{m})$. In recent years coal fines produced by the modern mechanized mining procedures has increased dramatically (Le Roux et al., 2005). Due to these modern methods, up to $15 \%$ of run-of-mine coal is in the $-500 \mu \mathrm{m}$ size fraction (England et al., 2002). Methods of dry fine coal beneficiation are therefore important to consider due to the vast amount of valuable fine coal that is discarded every year. 


\section{Experimental}

A $150 \mathrm{~mm}$ inner diameter fluidized bed column was designed and constructed from poly-carbonate material (Figure 1). It was assembled in a series of rings, clamped on top of one another to aid in the sampling after fluidization. After feeding the fluidized bed, it was operated for 15 minutes at a velocity just above the incipient fluidization point, where after the airflow was closed and the contents inside the chamber were allowed to settle. The material contained in different sections was then carefully removed and analyzed for density, calorific value and percentage ash (mineral content). As an added variable, vibration was added to the bed during some of the tests.

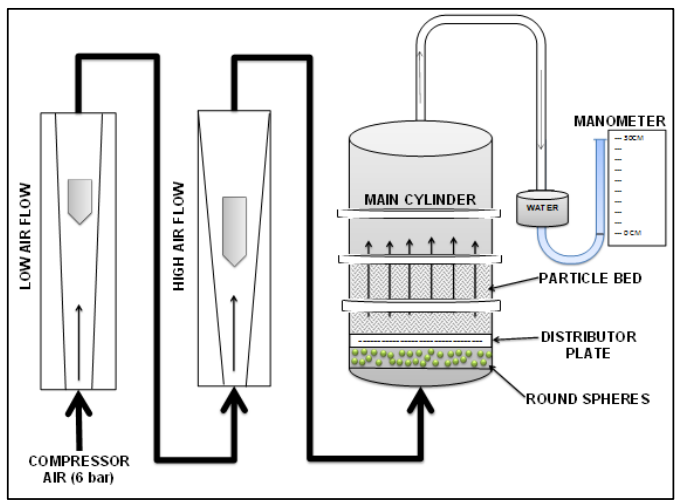

Figure 1: Fluidized bed setup.

Coal with two particle size distributions namely $-2+1 \mathrm{~mm}$ and $-1+0.5 \mathrm{~mm}$ was used together with three different media; fine sand $(-212 \mu \mathrm{m})$, magnitude $(-75 \mu \mathrm{m})$ and discard fine coal $(-500 \mu \mathrm{m}$ with $\mathrm{SG}=1.7)$. The mixtures were done on a weight base ratio medium to coal of 70:30 and 50:50. As a control a series of tests was done without media. The coal used in this study a typical South African bituminous coal of which the ash yield and calorific values are given in Table 1.

Table 1: Partial proximate and CV analysis

\begin{tabular}{|l|r|l|}
\hline & Value & Standard \\
\hline \% Inherent moisture content (air-dried) & 2.4 & ISO 11722: 1999 \\
\hline \% Ash content (air-dried) & 21.6 & ISO 1171: 2010 \\
\hline Calorific value (MJ $/ \mathrm{kg}$ ) (air-dried) & 24.5 & ISO 1928: 2009 \\
\hline
\end{tabular}

\section{Results and discussion}

An extensive set of results was generated during this project, of which only selected highlights are presented here. 

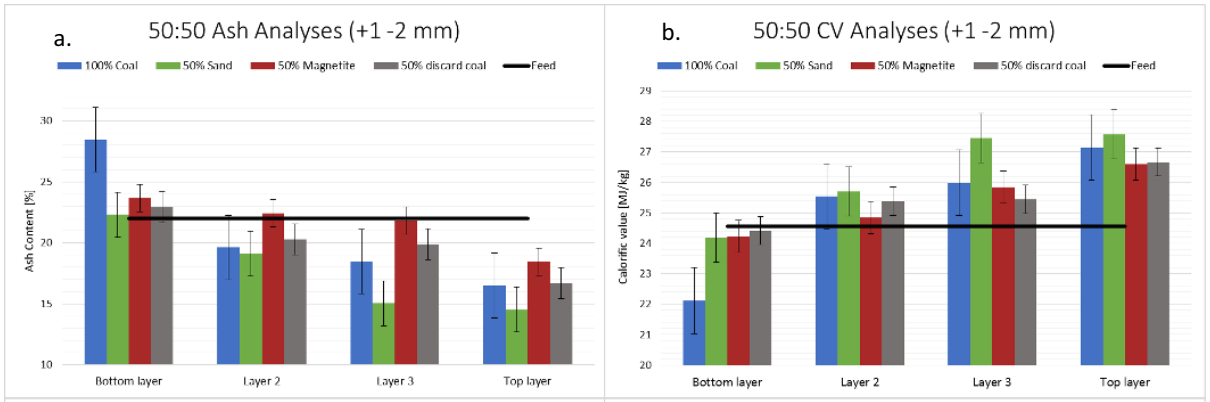

c. 50:50 Ash Analyses (+0.5 -1 mm)

d. $\quad 50: 50 \mathrm{CV}$ Analyses (+0.5 -1 mm)
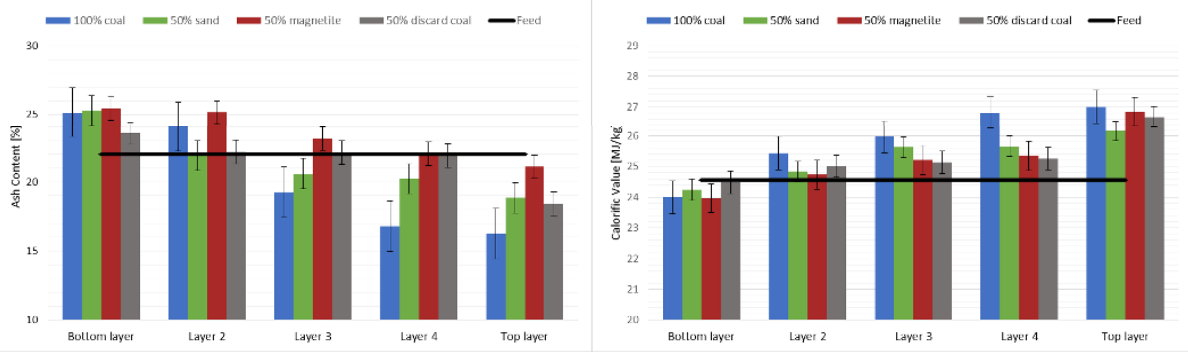

Figure 2: Results obtained for different PSD and mediums fed to a fluidized bed in a 50:50 ratio.

Figure 2 indicates the possibility of destoning fine coal using a fluidized bed. The graphs in Figures 2a. and $2 \mathrm{c}$. show a definite increase in ash yield percentage in the bottom part of the bed while Figures $2 \mathrm{~b}$. and $2 \mathrm{~d}$. indicate the corresponding increase in calorific value of the coal at the top part of the bed. The larger particles clearly show an increase in separability in relation to the smaller particles. This is attributed to smaller particle-particle contact surfaces for the larger particles, leading to lower frictional forces between the particles; increasing the ease in separation.

An unexpected result that was obtained for both PSD ranges was the increase in the sharpness of separation for the coal only fluidized beds in comparison to any of the dense media beds. The reason for the apparently poor performance of the dense media beds are attributed to the difficulty in recovering the dense media from the coal after fluidization. This was quantified by observation of the various colours of the residual coal ash during analysis as well as XRD performed on the coal ash. The combination of fine coal particles and ultra-fine dense media, especially the magnetite, increase the cohesion forces between the coal-coal, coal-media and media-media particles. Some of the dense medium particles also get trapped into the macro pores of the coal particles and then remain lodged there. Similar results were found for a bed with a medium to coal ratio of 70:30 and are therefore not shown.

The addition of vibration to the fluidized bed increased the destoning efficiency of the bed when operated both with and without any media. It opens up additional pathways for denser particles to settle to the bottom of the bed, therefore eliminating the amount of high density particle carry-over. This is especially true for smaller size percentages in each of the specific PSD feeds as well as when magnetite was added as a dense medium (Figure 3). This said, the resulting error-bars for both data sets do overlap 
to such a degree that a clear conclusion is difficult to reach. However, previous work done by Le Roux et.al. (2015) showed this effect to be real.
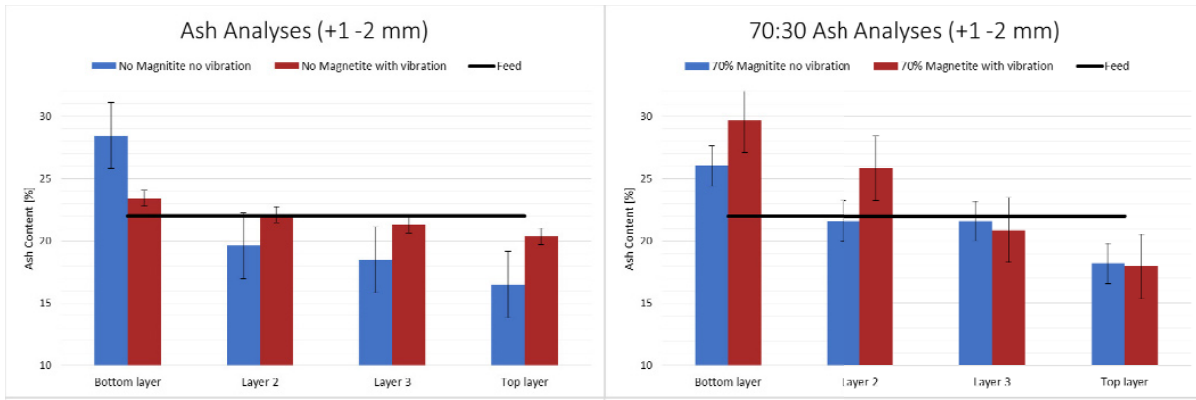

Ash Analyses (+0.5 -1 mm)
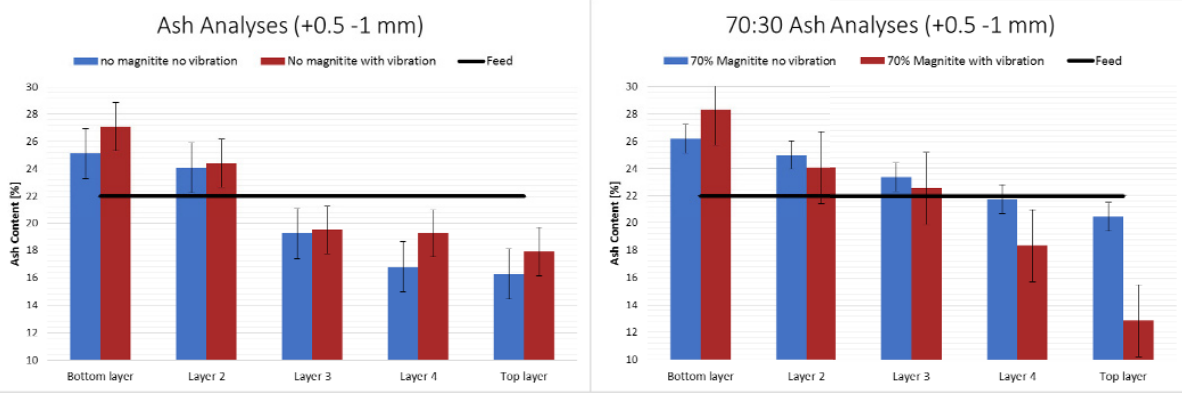

Figure 3: Comparison between vibration added to the bed and no vibration.

\section{Conclusions}

This paper investigated the possibility of upgrading $-2+1 \mathrm{~mm}$ and $-1+0.5 \mathrm{~mm}$ coal in a dry fluidized bed with and without added dense media. It showed that this technology is viable to achieve destoning in the bottom 20 to $30 \%$ of the bed especially if no dense medium was added. The addition of vibration to the bed does seem to increase the sharpness of separation during operations. The difficulty in recovery of the ultra-fine dense medium from the coal particles due to particle-medium adhesion and entrapment of the medium in the coal macro pores gave a false indication of the performance of the bed, but should be kept in mind in terms of overall plant performance.

\section{Acknowledgements}

The authors wish to acknowledge the financial and technical assistance of Coaltech. The contribution of our students Tylo Reibiero and Bendon Homan is recognised. This work is based on the research supported by the South African Research Chairs Initiative of the Department of Science and Technology and National Research Foundation of South Africa. Any opinion, finding, or conclusion or 
recommendation expressed in this material is that of the author(s) and the NRF does not accept any liability in this regard.

\section{References}

CHEN, Q. \& YANG, Y. 2003. Development of Dry Beneficiation of Coal in China. Coal Preparation, 23:3-12. 20 January.

CHEN, Q. \& WEI, L. 2003. Coal dry beneficiation technology in China: The state-of-the-art. China Particuology, 1(2):52-56. 18 March.

EBERHARD, A. 2011. The future of South African coal: Market, investment, and policy challenges. Stanford.

ENGLAND, T., HAND, P.E., MICHAEL, D.C., FALCON, L.M. \& YELL, A.D. 2002. Coal Preparation in South Africa. Pietermaritzburg: Natal witness commercial printers.

ERDENETSOGT, B.O., LEE, L., BAT-ERDENE, D. \& JARGAL, L. 2009. Mongolian coal-bearing basins: Geological settings, coal characteristics, distribution, and resources. International Journal of Coal Geology:87-104. 4 August.

HOUWELINGEN, J.A. \& DE JONG, T.P.R. 2004. Dry cleaning of coal: Review, fundamentals and opportunities. Geologica belgica, 7:335-343.

LE ROUX, M., CAMPBELL, Q.P., WATERMEYER, M. \& DE OLIVEIRA, S. 2005 The optimization of an improved method of fine coal dewatering. Minerals Engineering. 18(9): 931-934.

LE ROUX, M., CAMPBELL, Q.P. \& TERBLANCHE, N.T. 2015 The destoning of fine coal in a fluidized bed. 2015 Southern African coal processing society conference. Secunda. South Africa.

LEVIN, D. 2012. In Mongolia, New, Penned-In Wealth.

LUO, Z., ZHU, J., FAN, M., ZHAO, Y. \& TAO, X. 2007. Low Density Dry Coal Beneficiation Using an Air Dense Medium Fluidized Bed. Journal of China University of Mining \& Technology, 17:306309. 5 March.

MOHANTA, S., RAO, C.S., DARAM, A.B., CHAKRABORTY, S. \& MEIKAP, B.C. 2013. Air Dense Medium Fluidized Bed for Dry Beneficiation of Coal: Technological Challenges for Future. Particulate Science and Technology:16-27.

PHILANDER, G. 2010. www.cosechaypostcosecha.org. Date of access: 16 October 2011.

SAHU, A.K., BISMAL, S.K. \& PARIDA, A. 2009. Developement of air dense medium fluidized bed technology for dry beneficiation of coal - A review. International Journal of Coal Preparation and Utilization:216-241. 10 June.

YANG, X., ZHAO, Y., LI, G., LUO, Z., CHEN, Z. \& LIANG, C. 2012a. Establishment and Evaluation of a United Dry Coal Beneficiation System. International Journal of Coal Preparation and Utilization:95102. 20 March.

ZHAO, Y., LI, G., LUO, Z., LIANG, C., TANG, L., CHEN, Z. \& XING, H. 2011. Modularized dry coal beneficiation technique based on gas-solid fluidized bed. National Natural Science Foundation of China, 18:374-380. 10 December. 